\title{
A 32-Year-Old Coronary Thrombus Case Found during the COVID-19 Pandemic: Could It Be Caused By Sinovac Inactivated Vaccine Or COVID-19 Late-Term Complication?
}

\author{
Adem Aktan, Tuncay Güzel ${ }^{1}$ \\ Department of Cardiology, Mardin State Hospital, Mardin, 'Department of Cardiology, Gazi Yaşargil Training and Research Hospital, Health Sciences University, \\ Diyarbakır, Turkey \\ ORCID: \\ Adem Aktan: https://orcid.org/0000-0003-0505-9784 \\ Tuncay Güzel: https://orcid.org/0000-0001-8470-1928
}

\section{Abstract}

Coronavirus disease 2019 (COVID-19) infection is a public health problem, which globally is considered a pandemic, causing a significant level of morbidity and mortality. It has been defined as a viral infection, the etiology of which is unknown, causing mostly respiratory tract infections. It is surely beyond doubt that vaccine development also plays an important role in ending such pandemics as well as hygiene rules and personal protective equipment. It is becoming gradually more apparent that cardiovascular complications associated with COVID-19, such as myocardial damage, arrhythmia, acute heart failure, and venous thromboembolism, occur more frequently than what was thought before. The precise pathophysiological mechanisms of myocardial damage remain unclear but are thought to be the main pathway, with microthrombi, cytokine storm, and plaque rupture due to hypoxic damage, coronary spasm, direct endothelial, or vascular injury. In this study, we wanted to present a 32-year-old coronary thrombus case with no medical history and no risk factors, which we think may develop due to the Sinovac inactivated COVID-19 vaccine or as a late complication of COVID-19 disease. While cardiac side effects associated with inactive COVID-19 vaccines are still limited in the literature, this issue can be clarified if there are more case reports.

Keywords: Coronary thrombus, COVID-19, myocardial infarction, Sinovac inactivated vaccine

\section{INTRODUCTION}

Coronavirus is an enveloped RNA virus belonging to the Coronaviridae family. ${ }^{[1]}$ COVID-19 virus, also known as severe acute respiratory syndrome coronavirus 2 (SARS-CoV-2), was first discovered in Hubei province of Wuhan city in China in December 2019. It has been defined as a viral infection, the etiology of which is unknown, causing mostly respiratory tract infections. ${ }^{[2]}$ The virus first spread quickly within the city and then worldwide. It has become a serious public health problem with its increasing rate of spread and was confirmed as a "Pandemic" by the World Health Organization in 2020. It is known to frequently cause symptoms such as fever, shortness of breath, cough, muscle pain, myalgia,

\section{Received: 05-10-2021 Revised: 19-11-2021 Accepted: 02-12-2021}

Published Online: 29-01-2022

\begin{tabular}{|l|l|}
\hline \multicolumn{3}{|c|}{ Access this article online } \\
\hline Quick Response Code: & Website: \\
& \\
&
\end{tabular}

and weakness. In addition, there are studies showing that a number of thrombotic events related to COVID-19 infection have increased. ${ }^{[3,4]}$ It has been reported that it also causes pulmonary embolism as well as frequently causing venous thromboembolism and cerebral infarctions. ${ }^{[5-8]}$ Even though it is less common, it may lead to renal artery thrombosis, myocardial damage, and mesenteric ischemia. ${ }^{[9-12]}$ Although they are observed less frequently, thrombotic complications lead to a more serious and destructive course of the disease. While clinical evidence of thrombosis events associated

Address for correspondence: Dr. Adem Aktan, Department of Cardiology, Mardin State Hospital, Mardin, 47000, Turkey. E-mail: dradem21@hotmail.com

This is an open access journal, and articles are distributed under the terms of the Creative Commons Attribution-NonCommercial-ShareAlike 4.0 License, which allows others to remix, tweak, and build upon the work non-commercially, as long as appropriate credit is given and the new creations are licensed under the identical terms.

For reprints contact: WKHLRPMedknow_reprints@wolterskluwer.com

How to cite this article: Aktan A, Güzel T. A 32-Year-Old Coronary thrombus case found during the COVID-19 Pandemic: Could it be caused by sinovac inactivated vaccine or COVID-19 late-term complication? Int J Cardiovasc Acad 2021;7:140-3. 
with COVID-19 infection has been demonstrated, its pathophysiology is still an active field of research. ${ }^{[13]} \mathrm{In}$ pathology studies conducted on COVID-19 patients, it has been shown to cause diffuse microthrombi. These effects occur through complement-mediated microvascular damage in the lung and skin. ${ }^{[14,15]}$ It is known that SARS-CoV-2 infects the angiotensin-converting enzyme-2 (ACE-2) receptor found in endothelial cells at an early stage. According to the researches on the molecular pathogenesis of the disease defined as endotheliitis, it causes the accumulation of inflammatory cells and microcirculatory disorder ${ }^{[16]}$ It has been shown in recent studies that COVID-19 infection significantly increases procoagulants associated with acute phase reactants, leading the authors to hypothesize that the systemic inflammatory response is a significant contributor to thrombogenesis. ${ }^{[17]}$ In a study of early-stage conducted in Wuhan, China, a $12 \%$ myocardial injury rate was reported in patients with COVID-19 infection based on biomarker elevation. ${ }^{[18]}$

In this study, we wanted to present a case of coronary thrombus, which we think may develop due to the Sinovac inactivated COVID-19 vaccine or as a late complication of COVID-19 disease.

\section{Case Report}

The patient was a 32-year-old female patient who was admitted to the emergency room. She complained of chest pain, sweating, and palpitations spreading to her left arm for about $6 \mathrm{~h}$. Fever was $36.7^{\circ}$, respiratory rate $22 / \mathrm{min}$, blood pressure $110 / 70 \mathrm{~mm} / \mathrm{Hg}$, and $\mathrm{SpO}_{2} 97 \%$. On physical examination, lung breathing sounds were normal; heart sounds were rhythmic and normal. The electrocardiogram (ECG) was in sinus rhythm and the heart rate was $97 / \mathrm{min}$, with no pathology found [Figure 1]. The ejection fraction was evaluated within normal limits in the echocardiography image. No significant pathology was detected in the heart valves. In her medical history, she had a depot progesterone derivative. She did

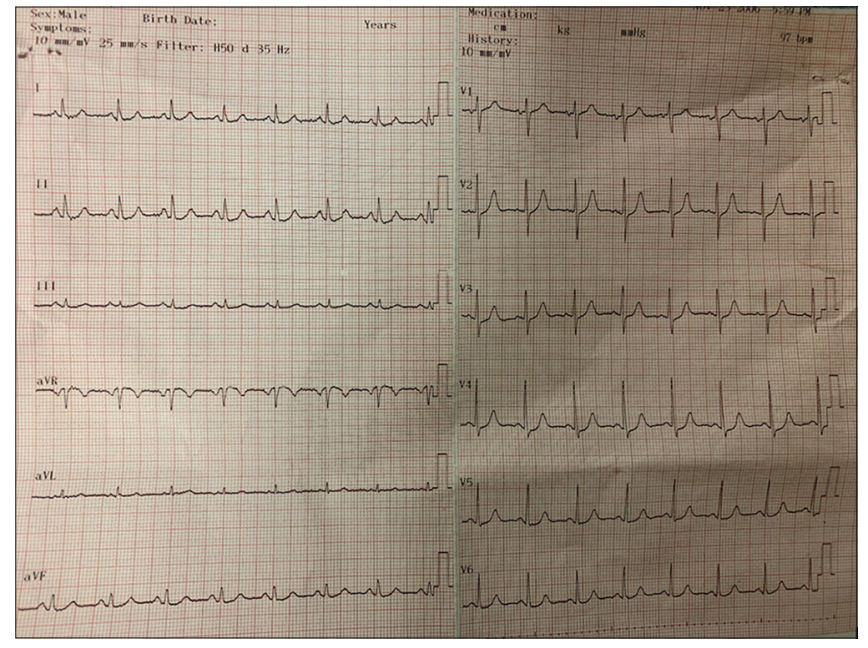

Figure 1: Electrocardiogram of the patient at the time of admission to the emergency department not use drugs, cigarettes, or alcohol. She was not pregnant. There was no history of chronic illness. She had a COVID-19 infection 3 months ago. She was not hospitalized while infected with COVID-19 disease. At that time, there were symptoms of widespread muscle pain, weakness, and loss of taste. She did not use any medications during the COVID infection. No pathology was found on thorax computed tomography taken in the emergency room. The Sinovac inactive $1^{\text {st }}$ dose COVID vaccine was administered 50 days ago, and the Sinovac inactive $2^{\text {nd }}$ dose COVID vaccine was administered 20 days ago. A progressive increase was observed in serial troponin levels, which were monitored at 3-h intervals in the emergency department $(0 \mathrm{ng} / \mathrm{mL}-1.19 \mathrm{ng} / \mathrm{mL}-7.77 \mathrm{ng} / \mathrm{mL}$, [determined reference range: $0-0.06 \mathrm{ng} / \mathrm{mL}$ ]). No significant pathology was found in biochemical, hemogram parameters, and infection markers. All coagulation parameters and D-dimer obtained from the patient were within normal limits. The global registry of acute coronary events score was 58 points and the thrombolysis in myocardial infarction risk score was calculated as 2 . Coronary angiography was decided because the patient's troponin values increased and his angina continued. The patient was taken to the catheter laboratory with a diagnosis of non-ST-elevation myocardial infarction. In the coronary angiography performed, an appearance compatible with thrombus in the distal left anterior descending artery was observed. No pathology was observed in circumflex and right coronary artery [Figure 2]. Two hundred microgram nitrate was administered intracoronary. However, abciximab treatment was planned because angina persisted, there was no significant atherosclerotic plaque, and the appearance consistent with thrombus continued. Abciximab (glycoprotein $2 \mathrm{~b} / 3 \mathrm{a}$ inhibitor) was given as an intracoronary bolus of $15 \mathrm{mg}$, followed by a systemic venous route for $12 \mathrm{~h}$ as $7.5 \mu \mathrm{g} / \mathrm{min}$ maintenance therapy. The procedure was finalized. Afterward, acetylsalicylic acid, clopidogrel, and enoxaparin treatments were ordered, and the patient was taken to the coronary

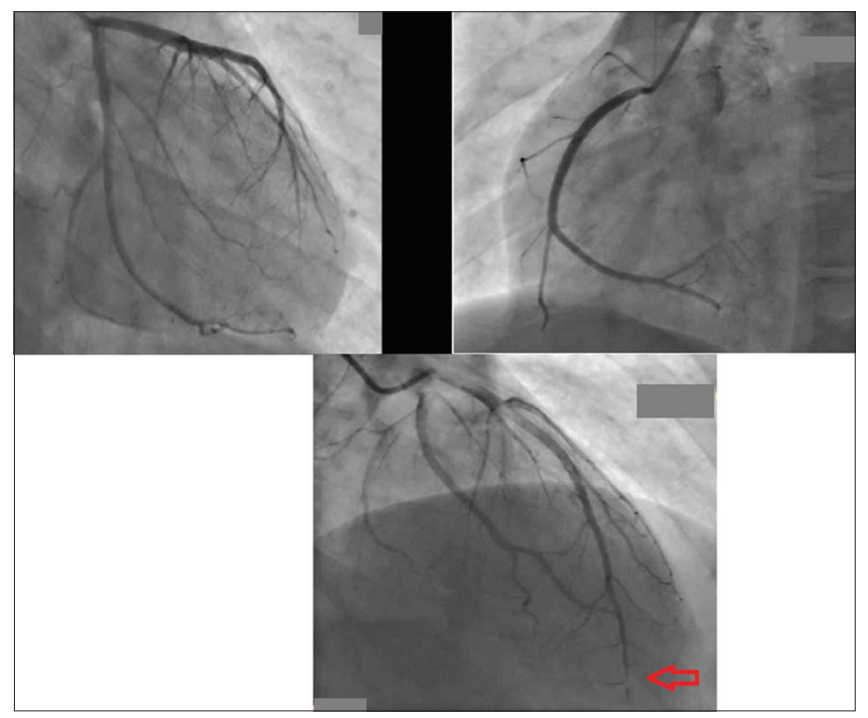

Figure 2: Coronary angiography images of the patient. Red Arrow: thrombus distal to the left anterior descending artery 
intensive care unit for follow-up. In addition, a maintenance dose of abciximab was given in the intensive care unit. The antiphospholipid antibody, antithrombin-3, protein-C, protein-S, factor V Leiden mutation levels in the blood after the procedure resulted in the normal reference range. In the control echocardiography examined at the bedside on the $2^{\text {nd }}$ day after the procedure, again no wall motion defect was seen. Control coronary angiography was not planned due to a decrease in troponin follow-ups $(4.58-2.27 \mathrm{ng} / \mathrm{mL})$, no dynamic changes in ECG follow-ups, and improvement in the patient's symptoms. The patient was discharged $72 \mathrm{~h}$ after the procedure.

\section{DISCUSSION}

Thrombotic complications from COVID-19 infection are well known, based on previous clinical studies and experience from in healthcare settings. In a study conducted during the COVID-19 outbreak, hospital admissions ascribed to acute coronary syndromes decreased by about $40 \%$. This rate most likely reflects the patient's preference to remain at home despite having symptoms, considering the risk of virus transmission in health-care facilities. ${ }^{[19]}$ The relationship between COVID-19 infection and cardiovascular disease has been well established. Studies show that patients infected with SARS-CoV-2 have an increased risk of severe disease and death if they have a medical history of cardiovascular disease. ${ }^{[20]}$ Elevation of cardiac enzymes is associated with more severe cases of COVID-19 and higher mortality. It is becoming increasingly clear that cardiovascular complications associated with COVID-19, such as myocardial damage, arrhythmia, acute heart failure, and venous thromboembolism occur at higher frequencies than previously thought. ${ }^{[21]}$ The mechanism of heart damage is thought to be multifactorial. SARS-CoV-2 infection occurs through receptor-mediated endocytosis triggered by the binding of the viral spike protein to the ACE-2 receptor on the host cell. The ACE-2 receptor is highly expressed in myocardial tissue, and this can function as a direct invasion pathway for the virus to disease-causing myocardial tissue. ${ }^{[22]}$ The virus can also cause systemic inflammation that leads to cytokine storm, which can develop into multi-organ system failure, including the cardiovascular system. ${ }^{[18,20]}$ Respiratory failure and the subsequent hypoxemia can lead to increased supply and demand mismatch and thus acute myocardial damage. SARS-CoV-2 is also thought to trigger a prothrombotic state that leads to the formation of microthrombi that can go on to form emboli. It leads to an acute ischemic event of the target end organ ${ }^{[23]}$ This mechanism may be what we think occurs in our young patient. The precise pathophysiological mechanisms of myocardial damage remain unclear, but as aforementioned, microthrombi, cytokine storm, and hypoxic damage are thought to be the main pathway, along with plaque rupture, coronary spasm, or direct endothelial or vascular injury. Our patient did not have an active COVID-19 infection. There were no risk factors for coronary artery disease, and there was no history of drug use that increased the risk of thrombus. We did not come across any significant pathology that increases the susceptibility to thrombosis in the thrombophilia panels. The fact that our patient had a history of COVID-19 as of few months ago and had an inactive COVID-19 vaccine in the recent past indicates that the coronary thrombus event that occurred-if there is no late complication of COVID-19 infection-may demonstrate such a complication after inactive COVID-19 vaccines. We wanted to discuss this issue. We require more case series and large-scale studies on this subject. To our knowledge, this is the first case report showing that coronary thrombus may develop after an inactive COVID-19 vaccine.

\section{ConcLusion}

COVID-19 infection is a public health problem, which globally is considered a pandemic, causing a significant level of morbidity and mortality. Without a doubt, vaccine development has an important role in ending pandemics as well as hygiene protocol and personal protective equipment. Studies are continuing to demonstrate the effectiveness and reliability of the vaccines that receive emergency approval for use. In this case study, we wanted to report a rare case of coronary embolism where we could not find any underlying cause, which we believe that this situation may be a delayed complication of COVID-19 disease or a rare complication of inactive COVID-19 vaccination.

\section{Declaration of patient consent}

The authors certify that they have obtained all appropriate patient consent forms. In the form, the patient(s) has/have given his/her/their consent for his/her/their images and other clinical information to be reported in the journal. The patients understand that their names and initials will not be published and due efforts will be made to conceal their identity, but anonymity cannot be guaranteed.

\section{Financial support and sponsorship}

Nil.

\section{Conflicts of interest}

There are no conflicts of interest.

\section{RefEREnCes}

1. Ali M, Mujahid A, Sherani K, Surani S. ST-elevation myocardial infarction in a 27-year-old male with COVID-19. Cureus 2020;12:e10384.

2. Lake MA. What we know so far: COVID-19 current clinical knowledge and research. Clin Med (Lond) 2020;20:124-7.

3. Klok FA, Kruip MJ, van der Meer NJ, Arbous MS, Gommers DA, Kant KM, et al. Incidence of thrombotic complications in critically ill ICU patients with COVID-19. Thromb Res 2020;191:145-7.

4. Helms J, Tacquard C, Severac F, Leonard-Lorant I, Ohana M, Delabranche $\mathrm{X}$, et al. High risk of thrombosis in patients with severe SARS-CoV-2 infection: A multicenter prospective cohort study. Intensive Care Med 2020;46:1089-98.

5. Dolhnikoff M, Duarte-Neto AN, de Almeida Monteiro RA, da Silva LF, de Oliveira EP, Saldiva PH, et al. Pathological evidence of pulmonary thrombotic phenomena in severe COVID-19. J Thromb Haemost 2020;18:1517-9.

6. Reddy ST, Garg T, Shah C, Nascimento FA, Imran R, Kan P, et al. 
Cerebrovascular disease in patients with COVID-19: A review of the literature and case series. Case Rep Neurol 2020;12:199-209.

7. Kaminetzky M, Moore W, Fansiwala K, Babb JS, Kaminetzky D, Horwitz LI, et al. Pulmonary embolism at CT pulmonary angiography in patients with COVID-19. Radiol Cardiothorac Imaging 2020;2:e200308.

8. Porfidia A, Valeriani E, Pola R, Porreca E, Rutjes AW, Di Nisio M. Venous thromboembolism in patients with COVID-19: Systematic review and meta-analysis. Thromb Res 2020;196:67-74.

9. Su H, Yang M, Wan C, Yi LX, Tang F, Zhu HY, et al. Renal histopathological analysis of 26 postmortem findings of patients with COVID-19 in China. Kidney Int 2020;98:219-27.

10. Zheng YY, Ma YT, Zhang JY, Xie X. COVID-19 and the cardiovascular system. Nat Rev Cardiol 2020;17:259-60.

11. Parry AH, Wani AH, Yaseen M. Acute mesenteric ischemia in severe coronavirus-19 (COVID-19): Possible mechanisms and diagnostic pathway. Acad Radiol 2020;27:1190.

12. Norsa L, Valle C, Morotti D, Bonaffini PA, Indriolo A, Sonzogni A. Intestinal ischemia in the COVID-19 era. Dig Liver Dis 2020;52:1090-1.

13. Capaccione KM, Leb JS, D'souza B, Utukuri P, Salvatore MM. Acute myocardial infarction secondary to COVID-19 infection: A case report and review of the literature. Clin Imaging 2021;72:178-82.

14. De Michele S, Sun Y, Yilmaz MM, Katsyv I, Salvatore M, Dzierba AL, et al. Forty postmortem examinations in COVID-19 patients. Am J Clin Pathol 2020;154:748-60.

15. Magro C, Mulvey JJ, Berlin D, Nuovo G, Salvatore S, Harp J, et al. Complement associated microvascular injury and thrombosis in the pathogenesis of severe COVID-19 infection: A report of five cases.
Transl Res 2020;220:1-13.

16. Varga Z, Flammer AJ, Steiger $P$, Haberecker $M$, Andermatt R, Zinkernagel AS, et al. Endothelial cell infection and endotheliitis in COVID-19. Lancet 2020;395:1417-8.

17. Masi P, Hékimian G, Lejeune M, Chommeloux J, Desnos C, Pineton De Chambrun $\mathrm{M}$, et al. Systemic inflammatory response syndrome is a major contributor to COVID-19 - Associated coagulopathy: Insights from a prospective, single-center cohort study. Circulation 2020;142:611-4.

18. Huang C, Wang Y, Li X, Ren L, Zhao J, Hu Y, et al. Clinical features of patients infected with 2019 novel coronavirus in Wuhan, China. Lancet 2020;395:497-506.

19. Mafham MM, Spata E, Goldacre R, Gair D, Curnow P, Bray M, et al. COVID-19 pandemic and admission rates for and management of acute coronary syndromes in England. Lancet 2020;396:381-9.

20. Driggin E, Madhavan MV, Bikdeli B, Chuich T, Laracy J, Biondi-Zoccai G, et al. Cardiovascular considerations for patients, health care workers, and health systems during the COVID-19 pandemic. J Am Coll Cardiol 2020;75:2352-71.

21. Welt FG, Shah PB, Aronow HD, Bortnick AE, Henry TD, Sherwood MW, et al. Catheterization laboratory considerations during the coronavirus (COVID-19) pandemic: From the ACC's interventional council and SCAI. J Am Coll Cardiol 2020;75:2372-5.

22. Chen Y, Liu Q, Guo D. Emerging coronaviruses: Genome structure, replication, and pathogenesis. J Med Virol 2020;92:418-23.

23. Anupama BK, Chaudhuri D. A review of acute myocardial injury in coronavirus disease 2019. Cureus 2020;12:e8426. 